INTERNATIONAL DESIGN CONFERENCE - DESIGN 2020

https://doi.org/10.1017/dsd.2020.75

\title{
ROLLING RESISTANCE OF ATV TYRES IN AGRICULTURE
}

\author{
T. C. Petterson ${ }^{\otimes}$ and S. D. Gooch \\ University of Canterbury, New Zealand \\ $\bigotimes$ tim.petterson@pg.canterbury.ac.nz
}

\begin{abstract}
Electric vehicles are playing an increasingly important role in the agricultural sector. The selection of tyres for reducing energy loss due to rolling resistance is an important consideration in determining the viability of these vehicles. To date little is known about rolling resistance of small all-terrain vehicles. In this study a test rig was used to collect rolling resistance data for seven ATV tyres. The study verifies the relationship between normal load and rolling resistance and gives insight into some of the important considerations when selecting tyres for small off road vehicles.
\end{abstract}

Keywords: rolling resistance, electric vehicles, optimisation, experimentation, energy efficiency

\section{Introduction}

As the world looks to reduce its environmental footprint, electric vehicles (EVs) are being implemented as a replacement for combustion vehicles on our roads. The environmental benefits, coupled with lower running costs, reduced noise, improvements in vehicle control and the compactness of EVs has resulted in their introduction into agricultural and off road environments. One of the major issues in developing an off road EV is maximizing the ratio of vehicle range over retail price. The cost of providing additional lightweight batteries is beyond that of an internal combustion (IC) competitor for the same vehicle range. An off road EV is being developed for use on a New Zealand dairy farm to perform various tasks autonomously, and is comparable to the size of a typical all-terrain vehicle (ATV) such as widely used $4 \times 4$ quad bikes or side-by-sides. IC ATVs have a superior range when compared to current electric ATVs, despite the inefficiencies of the combustion cycle. One way to improve efficiency and maximise range is to minimize the forces opposing the vehicle's motion. Of the four main opposing forces, "rolling resistance" is the only force constantly present throughout the vehicles motion. Rolling resistance results in significant energy losses due to deformation of tyre and terrain. However, due to the complex nature of tyres and ground conditions, rolling resistance for small off road tyres has been difficult to quantify.

This paper presents new data for rolling resistance of ATV tyres in an agricultural environment. This information is important due to the very limited amount of existing rolling resistance data available for ATV tyres. With road EV sales predicted to reach $28 \%$ of annual vehicle sales by 2030 , in New Zealand (NZ Govt., 2015), it can be expected that the demand for off road EVs will also increase significantly. A competitive, cost-effective EV cannot be developed without rolling resistance defined and minimised.

\section{Background and motivation}

Rolling resistance has a significant effect on vehicle motion, especially when operating off road. Although there is sufficient research into rolling resistance of tyres on hard surfaces (i.e. roads), there 
are few off road studies, and even less data is available for ATV tyre rolling resistance. ATV tyres are unique due to their size, design, operating environment and inflation pressure (typically $3-7 \mathrm{psi}$ ). This lack of data makes it very difficult to determine the power and battery requirements of a small off road EV. Using oversized components such as batteries and motors adds unnecessary extra weight to the vehicle, increases rolling resistance, and reduces commercial viability. Using undersized components would under power the vehicle making it unable to perform the functions that it was designed to do. Therefore, it is crucial that rolling resistance is defined for the chosen tyres.

EVs have limited battery capacity, therefore to maximize the vehicle's range the stored energy in the battery must be used as efficiently as possible. In this paper we will investigate the parameters that are associated with energy loss due to rolling resistance to determine how rolling resistance can be minimised to improve vehicle efficiency and range. Reducing rolling resistance will allow the implementation of smaller and lighter motors saving manufacturing cost reducing vehicle weight and reducing rolling resistance further.

\section{Factors affecting rolling resistance}

For off-road, zero gradient vehicle motion, rolling resistance is the only significant force opposing the vehicle's motion. The interaction between tyre and ground causes a loss in energy, as both tyre and ground are deformed. There are multiple mechanisms responsible for rolling resistance on medium to hard soil. These include energy loss due to the deflection of the tyre carcass and tread while rolling, scrubbing and tyre slip at the contact patch, deformation of the ground, and air drag both inside and outside of the tyre (Gillespie, 1992; Wong, 1993). A hysteresis is developed within the tyre due to repeated deformation and recovery. The overall rolling resistance is dependent on tyre properties, operating parameters and terrain conditions.

\subsection{Tyre factors}

As a tyre rotates, energy is consumed due to repeated deformation and recovery. The majority of this energy loss is caused by the viscoelastic behaviour of the rubber compound. Some of the energy stored is recovered once the load is removed, while the rest is converted to heat. This loss is known as hysteresis (Transportation Research Board, 2006). Wong (1993) shows that, for a tyre travelling between 128$152 \mathrm{kmhr}^{-1}$ on a road, $90-95 \%$ of the tyre energy loss is from hysteresis in the tyre. For a tyre that is travelling a lot slower, hysteresis losses will make up a larger percentage of the total energy lost, due to lower aerodynamic drag acting on the perimeter.

Tyre construction has a significant effect on tyre performance, life expectancy and rolling resistance. Its carcass is the most important structural element, typically designed using a bias-ply, radial or bias-belted construction. The bias-ply design has cords that extend diagonally across the carcass. During rotation, the diagonal plies flex, rub and elongate, producing a wiping motion between the tread and the ground. Consequently, the tyres wear faster and produce a higher rolling resistance. Radial tyres have cord layers extending radial across the carcass with belts fixed on top of the cords. Flexing of the carcass under rotation produces minimal relative movement of the belt cords, greatly reducing deformation and wiping of the tread at the contact patch (Wong, 1993). Kurjenluoma et al. (2009) and Transportation Research Board (2006) found that the coefficient of rolling resistance was 20-25\% lower for radial than for bias ply tyres. Bias ply tyres provide better grip and clean out in rough terrain due to their design allowing the entire tyre body to flex, so are typically used in low speed off road applications, such as ATVs. Figure 1 shows a comparison of the rolling resistance of the two tyre constructions. The type and quantity of rubber used and the number of plies as well as the tyre temperature affect rolling resistance.

The size of the tyre also influences its rolling resistance. This effect is often negligible on hard surfaces, such as concrete, but in off road terrain it is more pronounced. Steyn and Warnich (2014), Söhne (1969) and Bekker (1962) found that at the same inflation pressure, large diameter tyres produce less rolling resistance than smaller diameter tyres. Both tyre sizes deformed by the same amount (same pressure and load), but the tyre deformation in the smaller tyre is proportionally greater thus absorbing more of the wheel's rotational energy. The larger diameter tyre required less energy to overcome the tyre bugle at the contact patch due to the longer leverage provide by its greater diameter. 
The larger diameter also allows it to roll more easily across uneven terrain. Figure 2 shows as the diameter of the tyre increases, its rolling resistance decreases.

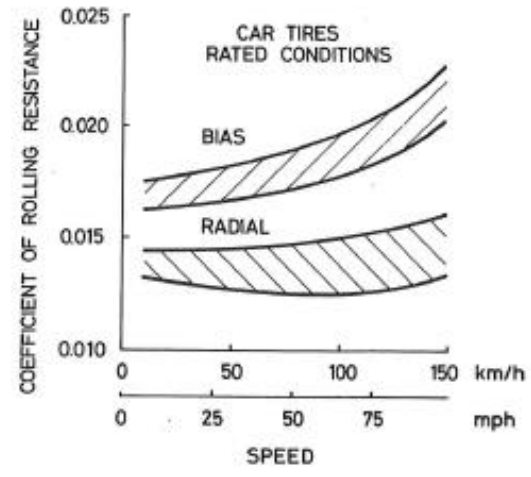

Figure 1. Rolling resistance comparison between radial and bias-ply car tyres $(\mathrm{GmbH}, 1986)$

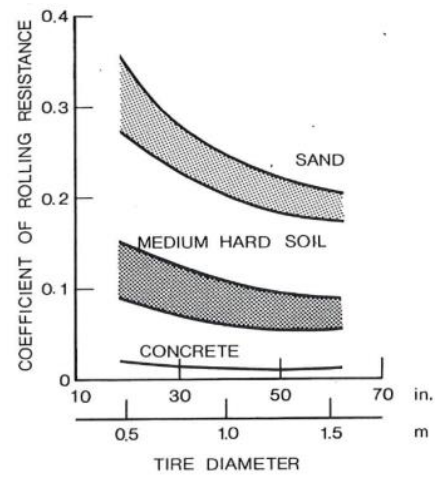

Figure 2. Tyre diameter's influence on rolling resistance (Wong, 1993)

Söhne (1969) and Bekker (1962) also investigated the effect the width of an agricultural tyre has on its rolling resistance. If a wide tyre and a narrow tyre were put under the same load and inflation pressure, the area of the contact patch would be the same. A narrow tyre has a long, slim contact path, whereas a wide tyre has a short, wide contact patch. Excessive length of the contact patch is detrimental to tyre rotation. A longer contact patch results in more tyre deformation in the direction of travel, causing the tyre's sidewalls to deflect more. The wider tyre deforms less in the rolling direction and maintains more energy. Bekker (1962) found that the diameter has a much stronger influence than width, which has little affect if the diameter is large.

ATV tyres are designed to be robust and provide excellent traction, with little concern for rolling resistance. Steyn and Warnich (2014) tested different mountain bike tread patterns and concluded that a smooth tread pattern rolls better than an open tread pattern. Tall lugs and wide lug spacing increases rolling resistance due to the roughness of the tyre surface. The tyre's tread is typically a high hysteresis rubber compound. As it wears down, the tyre's mass and amount of energy lost to hysteresis also reduces. On average, rolling resistance decreases by $20 \%$ across the life of the tyre (Transportation Research Board, 2006; Wong, 1993).

\subsection{Operating conditions}

The normal load in conjunction with inflation pressure has a significant effect on the rolling resistance of a tyre. For a set inflation pressure, an increase in normal load will increase the deflection in the sidewalls. The enlarged deformation increases the hysteresis experienced by the tyre, resulting in larger energy losses. For passenger vehicles, the relationship between sidewall deflection due to load and rolling resistance is approximately linear and therefore an increase in load typically results in a proportional increase in rolling resistance (Transportation Research Board, 2006; Gharibkhani et al., 2012). The proportional relationship outlines the significant influence mass has on rolling resistance and demonstrates that it should be minimized for the design of an efficient vehicle.

Inflation pressure influences the stiffness of the tyre and ground conditions dictate what inflation pressure will produce the least amount of rolling resistance. On hard surfaces, a higher inflation pressure will generally produce less tyre deformation and reduce the energy loss. However, if a high inflation pressure were used on a soft soil, the tyre would experience a higher rolling resistance than if a low pressure were used. This is due to the increased ground penetration work caused by the smaller contact patch. The lower inflation pressure produces a larger contact patch due to the large deformation of the sidewalls. This decreases ground deformation, but will also increase the energy lost to tyre deformation. McAllister (1983), Elwaleed et al. (2006) and Kurjenluoma et al. (2009) all found through testing of agricultural tyres that a lower inflation pressure reduced the rolling resistance of the tyres in soft soil conditions. However, Elwaleed et al. (2006) did find that if the pressure was lowered too much, the rolling resistance increased greatly. Therefore, for a certain set of ground, loading and tyre variables, there will be an optimal inflation pressure that minimises rolling resistance. 
Increased velocity affects rolling resistance due to the increased work in deforming the tyre and the development of vibrations (Wong, 1993). This effect on a car tyre are displayed in Figure 1. Velocity has little effect at low speeds typically experienced with ATV tyres. Both Holloway et al. (1989) and Taghavifar and Mardani (2013) found that velocity did not have any effect on rolling resistance at the speeds of $16 \mathrm{kmhr}^{-1}$ and $32 \mathrm{kmhr}^{-1}$ and 0.7, 1.4 and $2 \mathrm{~ms}^{-1}$, respectively. However, Gillespie (1992) states that the influence of velocity becomes more noticeable when the inflation pressure is low.

\subsection{Environmental conditions}

The firmness of the ground has a significant effect on rolling resistance. Soft soils (e.g. sand), produce much higher resistive forces than hard surfaces (e.g. concrete). On hard surfaces, the main loss of energy is due to the deformation of the tyre. On soft surfaces, sinkage occurs and a volume of soil is displaced within the contact patch as the wheel rotates and the vehicle moves forward. Shear displacement or slip also occurs as the tyre obtains traction on the soft surface and this results in further energy loss. Motion resistance models for tyres in soft soils have been developed, however soft soils are not addresses in this study. Here we focus on rolling resistance on firm soils i.e. conditions with no noticeable sinkage.

The ground surface also plays an important role in rolling resistance. A rough surface will result in higher tyre deformation in localised areas, leading to rolling resistance increases of up to $33 \%$ (a car tyre on coarse seal-coated asphalt when compared to new concrete) (Wong, 1993). Tyres driven on rough macrotexture or microtexture will experience more deformation and suffer larger energy losses than those driven on smooth surfaces (Transportation Research Board, 2006).

\subsection{Previous studies}

As mentioned previously, there has been minimal data collected for rolling resistance of ATV tyres in off road conditions. Holloway et al. (1989) investigated the rolling resistance of 22x11R8 and 21x7R10 ATV tyres on hard packed clay. This yielded a variety of rolling resistance coefficients ranging from 0.05 to 0.09 . It was also concluded that the rolling resistance coefficient was independent from the normal load. Tyres have greatly developed since 1989, with the construction and design changing, and thus their properties and rolling resistance will have changed. The hard packed clay does not represent a dairy farm environment very well, as a dairy farm has long and short grass with soft, moist, soils underneath. The influence of other rolling resistance factors were also not accounted for in this study. Lever et al. (2006) conducted tests on a 500mm diameter ATV tyre driven on snow-covered frozen ground, with $2-10 \mathrm{~cm}$ of light fresh snow on top. The rolling resistance coefficient for the driven tyre was found to be 0.08. The environment tested by Lever et al. (2006) was vastly different to typical conditions encountered on a typical dairy farm in New Zealand.

\subsection{General rolling resistance equation}

It is widely accepted (Bosch, 1993) that the rolling resistance of a pneumatic tyre is proportional to the normal ground load. Equation 1 shows its general form.

$$
F_{R R}=\mu F_{N}
$$

Where $\mathrm{F}_{\mathrm{N}}$ is the normal ground load and $\mu$ is the coefficient of rolling resistance for a given combination of tyre properties, operational factors and environmental conditions. The coefficients are well known for most road tyres, but as discussed earlier, largely unknown for ATV tyres in off road environments.

\section{Rolling resistance data collection}

\subsection{Test rig and testing environment}

A test rig, Figure 3, was design and manufactured at the University of Canterbury. The test rig consisted of a simple A-frame that was towed behind a vehicle, which allowed the tyres, normal load, and inflation pressure to be changed easily in the field. A $200 \mathrm{~kg}$ load cell was placed between the front of the frame and the trailer coupling. Two vertical pipes located gym weights directly above the wheel axle centres, so that the full weight load contributes to the normal tyre force i.e. not supported by the trailer coupling. The wheels were set to zero chamber and aligned parallel to each other. The test rig's wheel track was 
smaller than that of the tow vehicle. The normal load from the bare frame supported purely by the two wheels was measured to be $19.7 \mathrm{~kg}$. The force from the load cell was measured in parallel with the test rig's velocity. A Hall Effect sensor measured the wheel's angular velocity. The linear vehicle velocity was calculated using the rolling radius. It was assumed no slip occurred, as the wheels were towed.

The test rig was towed around a path set up on a dairy farm in Canterbury, New Zealand. It consisted of short grass (10-70mm tall), long grass $(200-250 \mathrm{~mm}$ tall) and a hard packed laneway. The surfaces were considered relatively flat and smooth. Testing took place in the last week of September 2018. The weather remained consistently fine over the week of testing, with no significant rain. The ground conditions were firm, with no sinkage experienced by either the tow vehicle or the test rig. The soil type in this area is a slit loam soil. Grass cover was consistent across the test route. Figure 4 shows the testing environment, the path and the speed $\left(10\right.$ or $\left.20 \mathrm{kmhr}^{-1}\right)$ that the test rig travelled.

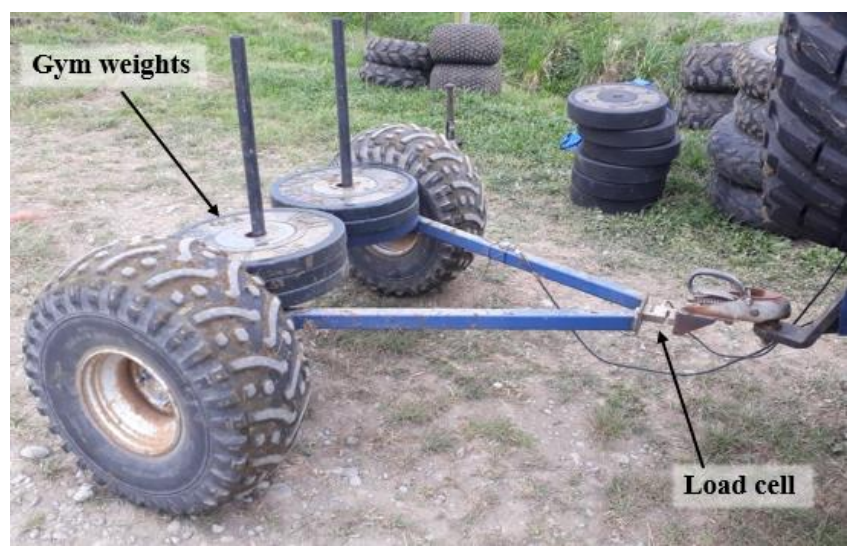

Figure 3. Towed test rig

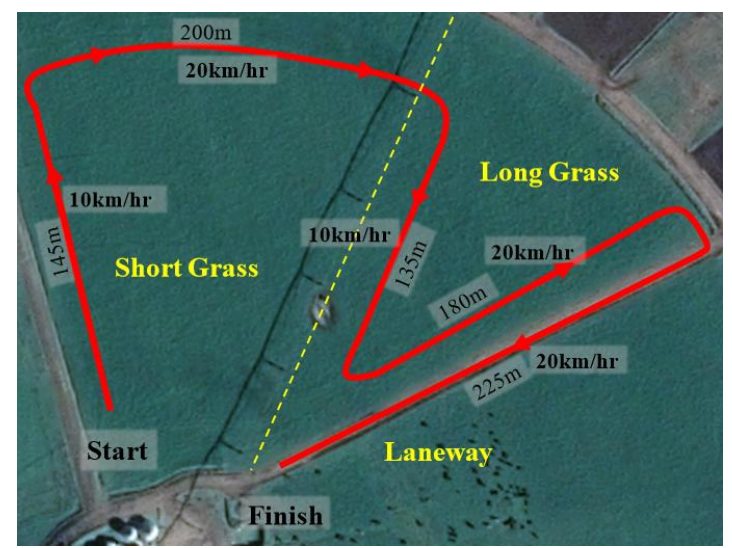

Figure 4. Testing route on dairy farm

\subsection{Testing variations and data processing}

Seven different pairs of ATV tyres were tested. Table 1 shows the tyres tested with their relevant information. The normal load was adjusted by adding gym weights to the test rig as show in Figure 3. Five normal loads were tested on the seven tyres, which ranged from $19.7 \mathrm{~kg}$ (bare test rig) to $229.7 \mathrm{~kg}$. All tyres operated at 5psi, except tyre two whose inflation pressure was adjusted from 2psi to $11 \mathrm{psi}$.

LABVIEW was used to measure and collect the data at a rate of $50 \mathrm{~Hz}$. As shown in Figure 4, each run collected five sets of data for the different combinations of variables (load, inflation pressure, tyre, terrain and speed). Five runs of the same combination of variables were completed, with the average rolling resistance force along with its associated maximum absolute error calculated.

Table 1. Details of the seven tyres used in the experiment

\begin{tabular}{|c|c|c|c|c|c|c|c|}
\hline Tyre Number & 1 & 2 & 3 & 4 & 5 & 6 & 7 \\
\hline \multicolumn{8}{|l|}{$\begin{array}{l}\text { Tyres at same } \\
\text { relative scale }\end{array}$} \\
\hline Size (in) & $19 \times 7 R 8$ & $22 \times 11 R 8$ & $23 \times 8 R 11$ & $24 \times 10 \mathrm{R} 11$ & $25 \times 8 R 12$ & $25 \times 13 R 9$ & $27 \times 9 R 14$ \\
\hline Brand \& Model & $\begin{array}{l}\text { Dunlop } \\
\text { KT945 }\end{array}$ & $\begin{array}{l}\text { Bushmate } \\
\text { P323 }\end{array}$ & $\begin{array}{l}\text { Dunlop } \\
\text { KT576 }\end{array}$ & $\begin{array}{l}\text { Duro } \\
\text { Buffalo }\end{array}$ & $\begin{array}{l}\text { Dunlop } \\
\text { KT402 }\end{array}$ & $\begin{array}{l}\text { Cheng } \\
\text { ShinC828 }\end{array}$ & $\begin{array}{l}\text { STI XT } \\
\text { Outback }\end{array}$ \\
\hline Tread depth (mm) & 5 & 6 & 1 & 9.5 & 1 & 7.5 & 15 \\
\hline Diameter (mm) & 467 & 520 & 565 & 578 & 618 & 622 & 655 \\
\hline Construction & Bias Ply & Bias Ply & Bias Ply & Bias Ply & Bias Ply & Bias Ply & Bias Ply \\
\hline Ply Rating & 2 & 6 & 4 & 4 & 4 & 4 & 6 \\
\hline
\end{tabular}




\subsection{Results}

Figure 5 displays the rolling resistance force against normal load for the $19 \times 7$ tyre. The five different lines represent the five terrain and speed combinations.

Normal load vs rolling resistance for 19x7 ATV tyre

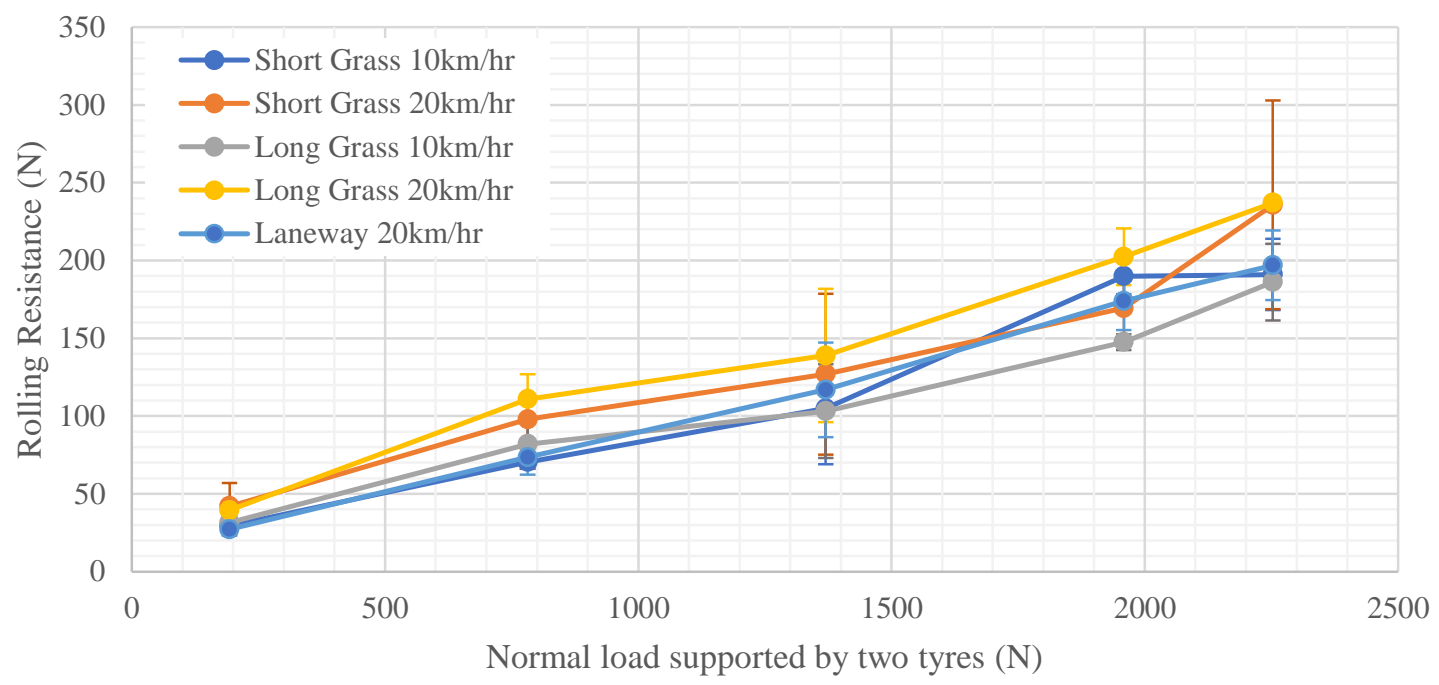

Figure 5. Rolling resistance force against normal load for "Tyre 1" (19x7")

All seven tyres produced similar linear patterns as displayed in Figure 6. As the normal load increased, the rolling resistance also increased at a proportional rate. Due to this relationship, the following graphs will be presented in terms of rolling resistance coefficients, where the rolling resistance force is divided by the normal load. Figure 6 compares the rolling resistance coefficients of the seven tyres. These rolling resistance coefficients with their associated uncertainties are shown in Table 2.

Rolling resistance coefficient comparsion of the seven tyres tested

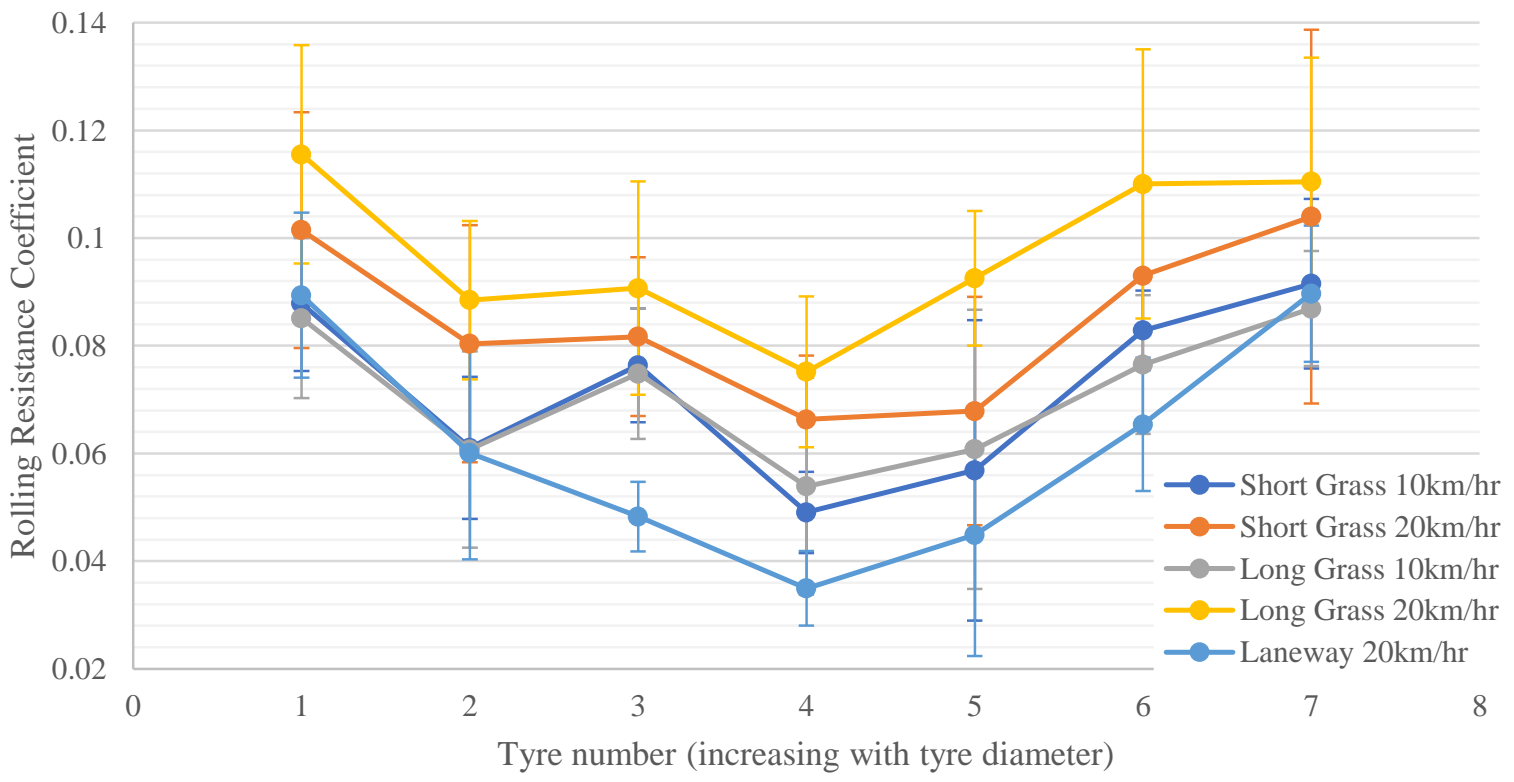

Figure 6. Rolling resistance coefficients of the seven tyres across the five terrain and speed combinations 
Table 2. Rolling resistance coefficients for the seven tyres tested

\begin{tabular}{|c|c|c|c|c|c|c|c|}
\hline Tyre & 1 & 2 & 3 & 4 & 5 & 6 & 7 \\
\hline Short Grass $10 \mathrm{kmhr}^{-1}$ & 0.09 & 0.06 & 0.08 & 0.049 & 0.06 & 0.083 & 0.09 \\
\hline Short Grass $20 \mathrm{kmhr}^{-1}$ & 0.10 & 0.08 & 0.08 & 0.07 & 0.07 & 0.09 & 0.10 \\
\hline Long Grass $10 \mathrm{kmhr}^{-1}$ & 0.09 & 0.06 & 0.07 & 0.05 & 0.06 & 0.08 & 0.09 \\
\hline Long Grass $20 \mathrm{kmhr}^{-1}$ & 0.12 & 0.09 & 0.09 & 0.08 & 0.09 & 0.11 & 0.11 \\
\hline Laneway $20 \mathrm{kmhr}^{-1}$ & 0.09 & 0.06 & 0.048 & 0.035 & 0.04 & 0.07 & 0.09 \\
\hline \multicolumn{8}{|l|}{ Uncertainties $( \pm)$} \\
\hline Short Grass $10 \mathrm{kmhr}^{-1}$ & 0.01 & 0.01 & 0.01 & 0.008 & 0.03 & 0.007 & 0.02 \\
\hline Short Grass $20 \mathrm{kmhr}^{-1}$ & 0.02 & 0.02 & 0.01 & 0.01 & 0.02 & 0.02 & 0.03 \\
\hline Long Grass $10 \mathrm{kmhr}^{-1}$ & 0.01 & 0.02 & 0.01 & 0.02 & 0.03 & 0.01 & 0.01 \\
\hline Long Grass $20 \mathrm{kmhr}^{-1}$ & 0.02 & 0.01 & 0.02 & 0.01 & 0.01 & 0.02 & 0.02 \\
\hline Laneway $20 \mathrm{kmhr}^{-1}$ & 0.02 & 0.02 & 0.006 & 0.007 & 0.02 & 0.01 & 0.01 \\
\hline
\end{tabular}

The uncertainties presented in Table 2 and Figures 5 and 6, show the maximum and minimum values obtained for the rolling resistance coefficients and forces, respectively. Figure 7 displays the relationship between inflation pressure and rolling resistance for the 22x11 ATV tyre. A normal load of $139.7 \mathrm{~kg}$ was kept constant across the different inflation pressures.

Inflation pressure vs rolling resistance coefficient for 22x11 ATV tyres

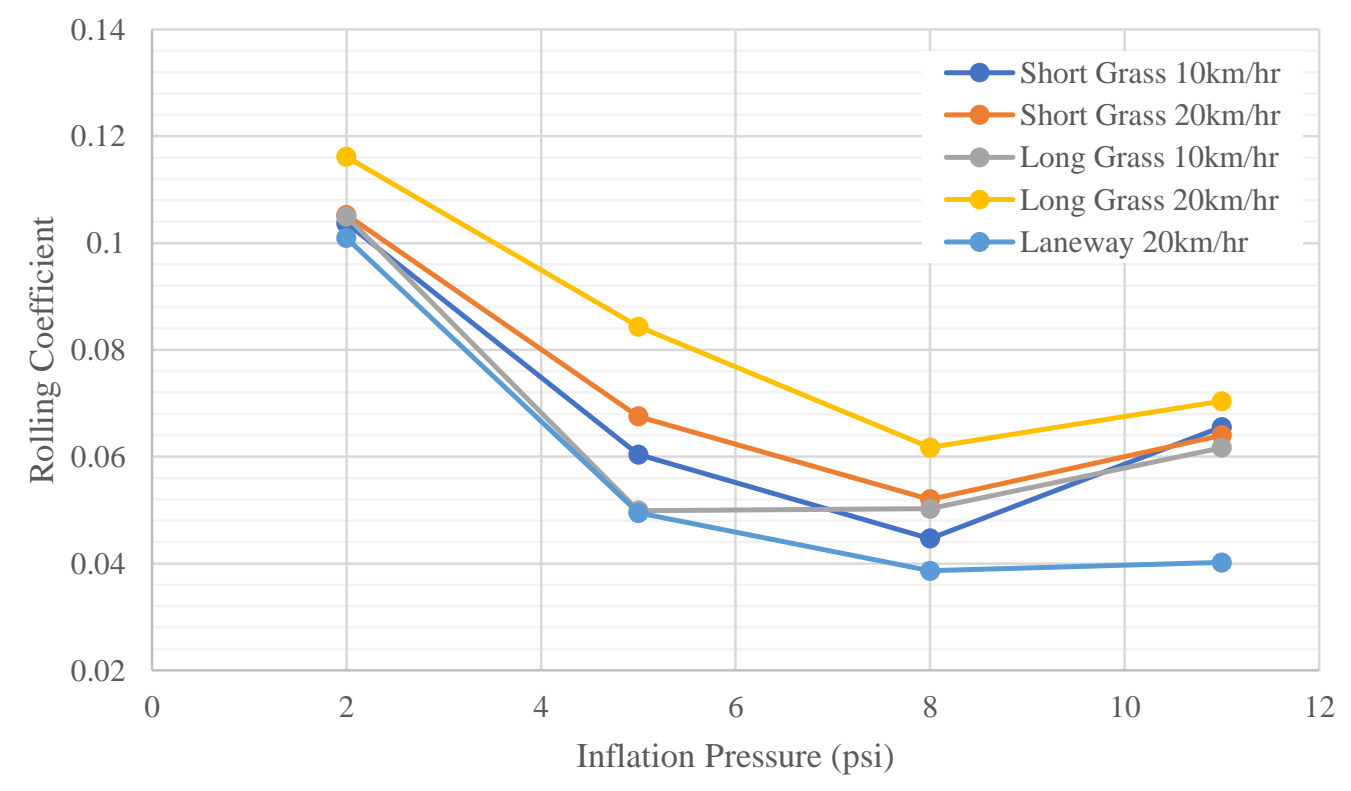

Figure 7. Relationship between inflation pressure and rolling resistance for $22 \times 11$ ATV tyres

\section{Discussion}

The main purpose of this study was to define the rolling resistant force for ATV tyres used in off road or agricultural environments. Table 2 shows the rolling resistance coefficients for all the tyres tested. With these coefficients determined, a lower rolling resistant tyre can be selected and the power and torque requirements can be accurately calculated for an ATV. This allows for correct sizing of motors and drivetrain components. This information is particularly useful for small off-road EVs. Choosing a tyre with lower rolling resistance will result in lower energy loss and allows for smaller and hence lighter drivetrain components to be used. This in turn reduces the vehicle's weight and consequently its rolling resistance. The battery capacity can then be optimized and the range accurately determined, producing a superior off road EV. 
The results of this study were found to be consistent with those reported earlier in the literature. The coefficient of rolling resistance measured for the $22 \times 11$ inch tyre (tyre 2) was between 0.06 and 0.09 . These results are similar to those reported by Holloway et al. (1989) for a similar size tyre with similar design features and construction. Lever et al. (2006) reported a coefficient of rolling resistance of 0.08 for a $500 \mathrm{~mm}$ diameter ATV tyre, on snow-covered frozen ground. The 19x7" tyre tested has a very similar diameter $(480 \mathrm{~mm})$, width and tread pattern to the tyre used by Lever et al. (2006). The coefficient of rolling resistance measured for the $19 \mathrm{x} 7$ " tyre was $0.09 \pm 0.01$ in the long grass, which is very similar to Lever's findings.

The rolling resistance data collected was for towed tyres. A driven wheel will produce slightly different values of rolling resistance due to the production of slip. However, since the testing was carried out on firm ground and not deformable terrain, the difference between driven and towed rolling resistance is expected to be negligible. The test rig was towed around the path displayed in Figure 4. This meant that the grass was repeatedly squashed due to the large quantity of runs completed. This may have slightly influenced the data. The rolling resistance measured for the lightest load (just the test frame) was higher than expected. This was due to the towed test frame bouncing due to the lack of weight. Consequently, this data was removed from the calculation of the rolling resistance coefficients as displayed in Table 2.

\subsection{Observed trends}

As seen in Figure 5, the rolling resistance data follows a linear pattern, where the rolling resistance is proportional to the normal load. This study has verified that the rolling resistance is proportional to the normal load for the ATV tyre sample tested. Therefore, the coefficient of rolling resistance must account for all the operational, environmental and tyre factors. These factors have varying influences on the rolling resistance and the complex behaviour of the tyre and ground interaction means that this coefficient often has to be determined experimentally.

All the tyres tested were of bias ply construction despite radial tyres having lower values of rolling resistance. Bias ply tyres dominate the ATV market due to their superior traction abilities, and durability. The bias ply construction allows the whole tyre to flex allowing the tyre to conform to the terrain, and produce better grip and cleanout than a radial equivalent. However, for the EV application where efficiency is the major factor a radial tyre would be selected. It has been found that bias ply tyres produce $20 \%$ more rolling resistance than their radial equivalents (Kurjenluoma et al., 2009), so it would be easy to determine the rolling resistance of radial ATV tyre s based off the data collected.

This study did not allow certain tyre properties to be isolated and compared directly to each other. This was largely due to the lack of resources and time available to complete testing. However, Figure 6 compares the rolling resistance of the seven tyres to each other. It can be seen that as the tyre diameter increases (from tyre one to four), the rolling resistance coefficient decreases from 0.09 to 0.049 (short grass $10 \mathrm{kmhr}^{-1}$ ). These four tyres have similar properties other than their change in diameter. This observed trend agrees with previous research. Tyre five has similar rolling resistant coefficients to tyre four, however, tyres six and seven have much higher values. Tyre six is significantly wider than the other tyres. This factor combined with its bias-ply construction, is responsible for its higher rolling resistance. The extra width, bias-ply construction and small rim means than the cord lengths are very long, which produces a greater wiping motion and a larger hysteresis cycle. The firm soil conditions meant no noticeable sinkage occurred, negating the floatation benefit of wider tyres. As discussed previously, wide tyres reduce rolling resistance when the diameter is small, however once the tyre diameter increases to a sufficient size, the increased width does not reduce rolling resistance. Tyre seven also produced high rolling resistance values, despite it having the largest diameter of the tyres tested. The reason for this high value is both the tread pattern and the tread depth. The tread depth $(15 \mathrm{~mm})$ was more than double that of the majority of the other tyres. This tread height coupled with the very wide aggressive tread pattern and firm ground conditions, produced a rough rolling motion. It had the effect of driving across corrugations on a gravel road. As discussed previously, rough terrain, or in this case rough tread, significantly increases the rolling resistance of a tyre. 
The effect of velocity of rolling resistance was shown to be important at the two speeds that were tested. It can be seen in the results that both the rolling resistance values for short and long grass at $20 \mathrm{kmhr}^{-1}$ were higher than their respective values at $10 \mathrm{kmhr}^{-1}$. This disagrees with the studies completed by Holloway et al. (1989) and Taghavifar and Mardani (2013), who state that velocity has little effect on rolling resistance at low speeds. At higher speeds, it has been well documented that velocity influences rolling resistance due to increased vibration and flexing of the tyre. Gillespie (1992) states the effect of velocity is small at low speeds, however when inflation pressure is low the influence of speed becomes more pronounced. The tyres were inflated to $5 \mathrm{psi}$, so this low pressure would explain why the velocity effect was noticeable at $10 \mathrm{kmhr}^{-1}$ and $20 \mathrm{kmhr}^{-1}$. Ground conditions also affected the rolling resistance. Of the three terrain conditions measured at $20 \mathrm{kmhr}^{-1}$, the laneway produced the least rolling resistance followed by the short then long grass. The laneway was clearly the smoothest and most compacted soil condition so it was expected it would produce the least resistance. Longer grass also slightly influenced the rolling resistance due to the increase amount of vegetation the tyres had to push through.

The inflation pressures for the $22 \times 11$ tyre were varied from 2 psi to $11 \mathrm{psi}$ as shown in Figure 7 . The normal load acting on the tyres was kept constant at $139.7 \mathrm{~kg}$. All terrain and speed combinations followed the same trend, with the rolling resistance reducing consistently from $2 \mathrm{psi}$ to $8 \mathrm{psi}$ and then slightly rising. The magnitude of rolling resistance halved, from $2 \mathrm{psi}$ to $8 \mathrm{psi}$ across all terrain and speed combinations. This produced a coefficient of $0.045 \pm 0.009$ at $8 \mathrm{psi}$ on short grass $\left(10 \mathrm{kmhr}^{-1}\right)$. There is clearly an optimal inflation pressure that produces the least amount of rolling resistance. Each tyre has a different set of properties and therefore different characteristics. An optimal inflation pressure that minimizes rolling resistance will be specific to not only the tyre design and construction, but also the environment and operating conditions. These factors determine how much the tyre and the ground deform. The inflation pressure can easily be adjusted to minimize energy loss due to the deformation of the tyre and ground. Therefore, this parameter should be tuned specifically to each vehicle and environment.

\section{Conclusion}

This paper has presented a study into rolling resistance of ATV tyres in an agricultural environment. A test rig was fabricated and towed behind a vehicle. The rolling resistance force was measured by a load cell in conjunction with the test rigs velocity. Seven different ATV tyres ranging from 460 to $655 \mathrm{~mm}$ in diameter were tested to determine their rolling resistance across various normal loads, terrains, inflation pressures and velocities. It was found that:

1. This study had verified that the normal load on ATV tyres is proportional to the rolling resistance for the ATV tyre sample tested;

2. Coefficient of rolling resistance has been defined for a range of operational, environmental, and tyre property combinations;

3. The rolling resistance coefficients for tested ATV tyres ranged from 0.035 to 0.12 . The lowest rolling resistance was found to be in the $24 \times 10$ tyre. It had a coefficient of 0.05 at a speed of $10 \mathrm{kmhr}^{-1}$ (grass) and 0.07 at $20 \mathrm{kmhr}^{-1}$ (grass);

4. The diameter of ATV tyres has a significant influence on the rolling resistance. The $19 x 7$ tyre produced nearly twice as much rolling resistance as the $24 \times 10$ tyre;

5. Significant tyre width and wide spaced, deep tread were found to have detrimental effects on rolling resistance even when the tyre's diameter is large;

6. Increased velocity at low speeds produces more rolling resistance. This affect is noticeable even at low speeds of $10 \mathrm{kmhr}^{-1}$ and $20 \mathrm{kmhr}^{-1}$ due to low inflation pressure;

7. Inflation pressure plays an important role in rolling resistance. There is an optimal inflation pressure for a certain tyre, terrain, loading and speed combination. For the $22 \times 11$ tyre tested, this optimal pressure was $8 \mathrm{psi}$, which produced a rolling resistance coefficient of 0.045 (10 $\mathrm{kmhr}^{-1}$ short grass).

Further work should involve the isolation of properties for ATV tyres so that each individual property can be quantified to determine its value in minimizing rolling resistance. From our observations, the main properties of interest are: outside diameter, overall tread width and tread type/depth. It is recommended that 
a comparison be made using the same tyre size with varying tread depths and patterns. The results of the study would allow the recommendation of the best tyre size and type for specific normal loads and ground conditions. Tyre width should also be studied, with the diameter and type of tyre fixed while varying the width to quantify the relationship between width and rolling resistance.

The use of radial tyres in small off road vehicles is desired due to their lower rolling resistance. Therefore testing of radial tyres should also be completed to accurately determine their energy consumption.

\section{References}

Bekker, M.G. (1962), Theory of land Locomotion, Michigan, United States of America. https://doi.org/10.3998/ mpub.9690401

Bosch, R. (1993), Automotive Handbook, 3rd ed., Robert Bosch.

Elwaleed, A. et al. (2006), "Effect of inflation pressure on motion resistance ratio of a high-lug agricultural tyre", Journal of Terramechanics, Vol. 43 No. 2, pp. 69-84. https://doi.org/10.1016/j.jterra.2004.08.006

Gharibkhani, M., Mardani, A. and Vesali, F. (2012), "Determination of wheel-soil rolling resistance of agricultural tire", Australian Journal of Agricultural Engineering, Vol. 3 No. 2, pp. 6-11.

Gillespie, T.D. (1992), Fundamentals of Vehicle Dynamics, Society of Automotive Engineers, Inc., Pittsburgh. https://doi.org/10.4271/r-114

GmbH, R.B. (1986), Automotive Handbook, 2nd ed., Germany.

Holloway, D., Wilson, W. and Drach, T. (1989), "Examination of ATV Tire Forces Generated on Clay, Crass, and Sand Surfaces", SAE International, United States of America, pp. 1064-1075. https://doi.org/10.4271/891106

Kurjenluoma, J., Alakukku, L. and Ahokas, J. (2009), "Rolling resistance and rut formation by implement tyres on tilled clay soil", Journal of Terramechanics, Vol. 46 No. 6, pp. 267-275. https://doi.org/10.1016/ j.jterra.2009.07.002

Lever, J. et al. (2006), "Solar power for an Antarctic rover", Hydrological Processes: An International Journal, Vol. 20 No. 4, pp. 629-644. https://doi.org/10.1002/hyp.6121

McAllister, M. (1983), "Reduction in the rolling resistance of tyres for trailed agricultural machinery", Journal of agricultural engineering research, Vol. 28 No. 2, pp. 127-137. https://doi.org/10.1016/0021-8634(83)90082-3

New Zealand Government (2015), Projections of Electric Vehicle Fleet Size, Ministry of Business, Innovation \& Employment, New Zealand.

Söhne, W. (1969), “Agricultural engineering and terramechanics”, Journal of Terramechanics, Vol. 6 No. 4, pp. 9-30. https://doi.org/10.1016/0022-4898(69)90002-0

Steyn, W.J. and Warnich, J. (2014), "Comparison of tyre rolling resistance for different mountain bike tyre diameters and surface conditions", South African Journal for Research in Sport, Physical Education and Recreation, Vol. 36 No. 2, pp. 179-193.

Taghavifar, H. and Mardani, A. (2013), "Investigating the effect of velocity, inflation pressure, and vertical load on rolling resistance of a radial ply tire", Journal of Terramechanics, Vol. 50 No. 2, pp. 99-106. https://doi.org/10.1016/j.jterra.2013.01.005

Transportation Research Board (2006), Tires and Passenger Vehicle Fuel Economy, National Research Council, Washington, D.C., Unites States of America.

Wong, J.Y. (1993), Theory of Ground Vehicles, 2nd ed., Wiley-Interscience, United States of America. 